\title{
Plant mediated synthesis of silver nanoparticles using Punica granatum aqueous leaf extract
}

\begin{abstract}
Punica granatum has been used for thousands of years to cure a wide range of diseases across different cultures and civilizations. The leaves of Punica granatum are used to calm stomach disorders, combat diarrhea, dysentery and hemorrhages, conjunctivitis etc. Recently the synthesis of nanoparticles mediated by plant leaf extracts for medicinal purposes is gaining grounds. Many workers have reported that the silver nanopartlces synthesized by aqueous leaf extracts are medicinally more efficient as compared to the leaf extracts itself. Thus in this study we report the synthesis and characterization of Punica granatum aqueous leaf extract mediated silver nanoparticles. For synthesis of the silver nanoparticles, the leaves of Punica granatum were collected and dried in shade and extracted in aqueous medium using Soxhlet extraction apparatus. The extract was used for synthesis of silver nanoparticles. The characterization of silver nanoparticles was done and the formation of silver nanoparticles was confirmed by change in the colour of solution from yellow to dark brown. The silver nanoparticles thus formed were subjected to UV-vis spectrophotometer, Scanning Electron Microscope (SEM), and Fourier-Transform Infra-red (FTIR) analysis for further characterization of the formed nanoparticles. Thus in this study we report the formation of silver nanoparticles in the range of 88.00 to $120 \mathrm{~nm}$ and average size of particles were confirmed to be $98.93 \mathrm{~nm}$.
\end{abstract}

Keywords: nanoparticles, Ag, FTIR, SEM, UV-vis, Punica granatum
Volume 6 Issue 4 - 2018

\author{
Manoj Kumar,' Sukumar Dandapat,' Rakesh \\ Ranjan,' Amar Kumar, ${ }^{2}$ Manoranjan Prasad \\ Sinha' \\ 'Department of Zoology, Ranchi University, India \\ ${ }^{2}$ Department of Zoology, KS College, India
}

Correspondence: Manoj Kumar, Department of Zoology, Ranchi University, Ranchi-834002, Jharkhand, INDIA, Tel +9| 97085 50235, Email dr17mk@gmail.com

Received: March 12, 2018 | Published: July 17, 2018
Abbreviations: FTIR, fourier-transform infra-red; SEM, scanning electron microscope; UV-vis, ultra violet-visible spectroscopy; SPR, surface plasmon resonance

\section{Introduction}

Biology of plant mediated nanoparticles is an upcoming branch of nanotechnology. Nanobiotechnology refers broadly to a field of science whose theme is control of matter at atomic and molecular scale. ${ }^{1}$ Synthesis of silver nanoparticles is of much interest to the scientific fraternity. Because of their wide range of applications. Silver nanoparticles are widely being used in cancer diagnosis and treatment as well. ${ }^{2,3}$ Prior to the green synthesis, the nanoparticles were prepared by a variety of chemical and physical methods which were quite expensive and potentially hazardous to the environment which involved use of toxic and perilous chemicals that are responsible for various biological risks. The development of biologically-inspired experimental processes for the syntheses of nanoparticles is evolving into an important branch of nanotechnology. ${ }^{4} \mathrm{~A}$ green method of synthesis of nanoparticles has several important applications in the field of biolabeling sensors, drug delivery systems, and filters. Nanoparticles possess antimicrobial activity and exhibit new physicochemical properties which are not observed in polar or non-polar extracts of plants. ${ }^{5}$

Biological routes of synthesis of metal nanoparticles have been proposed by exploiting bacteria, ${ }^{6}$ yeast, ${ }^{7}$ fungi, ${ }^{8}$ actinomycetes,,${ }^{9}$ and viruses,,$^{10}$ involved synthesis. The processes are not yet feasible for industry, and their pathogenicity and lab maintenance which require skilled technicians. Therefore the use of plant extracts for this purpose is potentiality advantageous over microorganisms due to the ease of improvement, the less biohazard and elaborate process of maintaining cell cultures. ${ }^{11}$
Punica granatum L., commonly known as pomegranate, is a fruit bearing deciduous shrub or small tree, native to Asia and belongs to family Lathraceae. ${ }^{12}$ The leaves are shiny and about $7.6 \mathrm{~cm}$ long. ${ }^{13}$ Different parts of plants such as leaves, bark and fruit have medicinal significance. ${ }^{14}$ Punica granatum has been used as traditional medicine in many countries for the treatment of dysentery, diarrhea, helminthiasis, acidosis, hemorrhage etc. ${ }^{15}$ Numerous phytochemical constituents have been reported to be present in different parts of Punica grantum plant, which makes it medicinally important. ${ }^{16}$ In this work we report the synthesis of silver nanoparticles, reducing the silver ions present in the solution of silver nitrate by the aqueous extract of Punica granatum. This method is faster and yields stable silver nanoparticles compared to other methods. The qualitative formations of nanoparticles were monitored by UV-vis spectroscopy. Also the silver nanoparticles formations were confirmed by reddish brown colour formation. ${ }^{17,18}$

\section{Materials and methods}

\section{Preparation of plant extract}

The fresh tender leaves of Punica granatum was collected from Ranchi district of Jhakrhand state of India. The leaves were washed with deionised water and disinfected with $0.1 \% \mathrm{HgCl}_{2}$ solution for 5minutes and dried in shade away from direct sunlight for 20days. The dried leaves were grounded to fine powder with the help of electrical grinder. 50g of the fine powder of leaf of Punica grantum was subjected to Soxhlet extraction using distilled water for aqueous extraction continuously for $72 \mathrm{hrs}$. The obtained extract was concentrated after filtration, using rotary flash evaporator at $45^{\circ} \mathrm{C}$. The extract was stored at room temperature in air tight bottles for further studies as per previously published standards. ${ }^{19}$ 


\section{Synthesis of silver nanoparticles}

For synthesis of nanoparticles, $1 \mathrm{ml}$ of Punica granatum leaf extract was added to $99 \mathrm{ml}$ of $1 \mathrm{mM} \mathrm{AgNO}_{3}$ solution. The mixture was allowed to stir for $2 \mathrm{hrs}$ at $90^{\circ} \mathrm{C}$. The mixture was allowed to cool down and after 2 hour, the mixture was centrifuged at $10000 \mathrm{rpm}$ for $15 \mathrm{~min}$ at room temperature. The supernatant was discarded and sediment was washed three times with distilled water. The resultant black powder was dried overnight in an oven at $80^{\circ} \mathrm{C} . .^{20,21}$

\section{Characterization of nano-particles}

Characterization of silver nanoparticles was done using UVvis spectrum analysis, SEM analysis, Fourier Transform Infrared Spectroscopy (FTIR) analysis.

\section{UV-visible spectrum analysis}

The reduction of pure $\mathrm{Ag}^{+}$ions was monitored by measuring the UV-visible spectrum of the reaction medium after $5 \mathrm{hr}$ after diluting a small aliquot of the sample into Milli-Q water. UV-visible spectral analysis was performed using Perkin Elmer, Lambda 25 UV-visible spectrophotometer (USA).

\section{SEM analysis}

SEM (Scanning Electron Microscopy) analysis was performed using JEOL JSM-6390 LV machine (Jeol, Japan). Thin films of the sample were prepared on a carbon coated copper grid by dropping a small amount of the sample on the grid, extra solution was removed using a blotting paper and then the film on the SEM grid was allowed to dry by putting it under mercury lamp for $5 \mathrm{~min}$ and was coated with gold using ion sputter.

\section{Fourier transform infrared spectroscopy (FT-IR) analysis}

FT-IR analysis was carried out on a Shimadzu IR-prestige-21 (Shimadzu Corpn., Japan) in the diffuse reflectance mode operated at a resolution of $4 \mathrm{~cm}^{-1}$ in the range of $400-4000 \mathrm{~cm}^{-1}$ to evaluate the functional groups that might be involved in nanoparticles formation.

\section{Results and discussion}

\section{UV-vis spectrophotometer analysis}

As soon as the Punica granatum leaf extract was mixed in the aqueous solution of the silver ion complex, colour change from yellow to dark brown was observed due to reduction of silver ion (Figure 1). This colour change is reportedly confirmation of formation of nanoparticles. ${ }^{22}$ The silver nanoparticles show yellowish brown colour in aqueous solution due to excitation of surface plasmon vibrations. ${ }^{23,24}$ It was observed that the after 60 minutes no further colour change was observed, this indicates that silver salt present in the reaction mixture was completely reduced. Then the formation of silver nanoparticles was examined and confirmed by obtaining the respective absorption spectra. The absorption spectrum originated due to strong surface plasmon resonance (SPR), i.e. due to resonant absorption of photons by silver nanoparticles. The observed absorption band is size dependent, since SPR band depends on size and refractive index of solution. ${ }^{25}$

A review of the literature revealed that the silver nanoparticles show SPR peak from 400-490nm. In this study the Punica granatum silver nanoparticles showed SPR peak at (255nm and) $420 \mathrm{~nm}$ (Figure 2). Dhanlakshmi \& Rajendran, ${ }^{26}$ reported SPR of $452 \mathrm{~nm}$ peak for silver nanoparticles synthesized using Tridax procumbens. Several studies have reported absorbance peak from 450-500nm for silver nanoparticle synthesis using Argemone Mexican, ${ }^{27}$ Papaya fruit extract, ${ }^{28}$ and Trianthema decandra. ${ }^{29}$ In our previous work with aqueous leaf extract of Swertia chirayita, we found a SPR peak at $450 \mathrm{~nm} \cdot{ }^{17}$

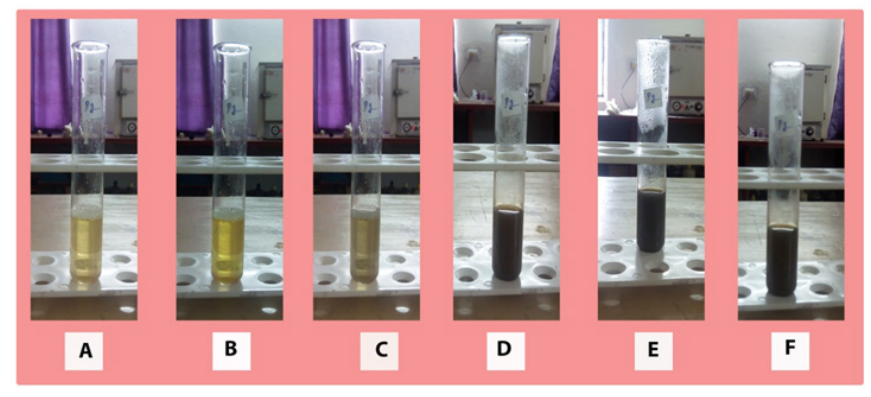

Figure I figure showing change in colour of aqueous solution from yellow to deep brown gradually from $A$ to $F$.

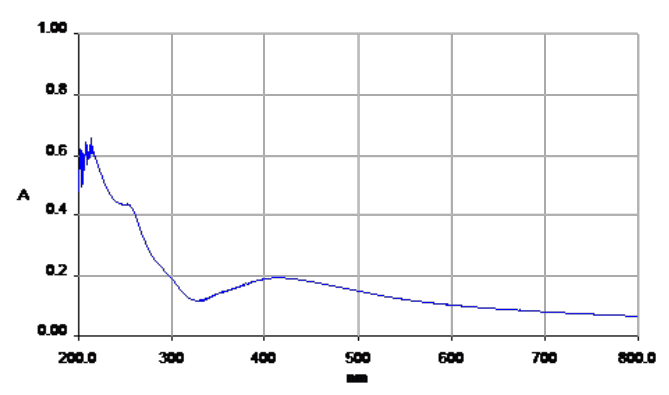

Figure 2 Result of UV-vis spectrophotometric analysis, showing peak at (255nm \& 420nm).

\section{SEM analysis}

The size and structure of silver nanoparticles synthesized with Punica granatum aqueous leaf extract was further subjected to SEM analysis to examine the morphology of the nanoparticles. The Punica granatum leaf extract mediated synthesized silver nanoparticles were spherical, rhomboid and cubical in shape and had diameter of nanoparticles ranged from $88.0-120 \mathrm{~nm}$ and average size of particles were $98.93 \mathrm{~nm}$. Kumar et al., ${ }^{19}$ reported the size of alion mediated synthesized nanoparticles to be in range of $287-293 \mathrm{~nm}$ and average size was $70 \mathrm{~nm}$. Firdhouse et al., ${ }^{30}$ reported the size of silver nanoparticles synthesized by ethanolic leaf extract, ranging from 20 $150 \mathrm{~nm}$ in diameter (Figure 3).

\section{Fourier transform infrared spectroscopy (FT-IR) analysis}

FT-IR analysis was carried out to analyze the role of the plant extract functional groups, and as a capping agent and bioreduction agent. ${ }^{31,32}$ FT-IR absorption spectra of green Ag nanoparticles is presented as Figure 4. The spectra observed by FT-IR analysis was compared with reference value previously published by Coates..$^{33}$ The spectra showed broad transmission peak at $3633.69 \mathrm{~cm}^{-1}$, which corresponds to hydrogen bonded hydroxyl group (O-H and $\mathrm{H}$ stretch) of alcohols and phenols. The $2102.44 \mathrm{~cm}^{-1}$ peak corresponds to $-\mathrm{SCN}$. 
The $1500.62 \mathrm{~cm}^{-1}$ peak corresponds to $\mathrm{C}=\mathrm{C}$ stretch, which represents alkenes, $1361.74 \mathrm{~cm}^{-1}$ corresponds to sulphonates, and $937.40 \mathrm{~cm}^{-1}$ corresponds to $\mathrm{C}=\mathrm{N}$ stretch that represents aliphatic amines. ${ }^{34}$
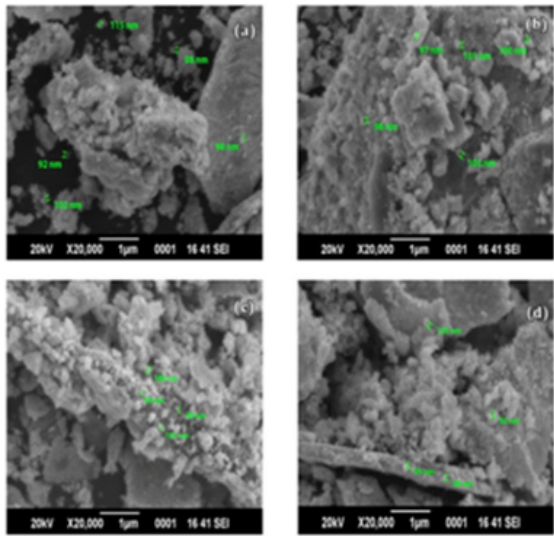

Figure 3 SEM images of Punica granatum mediated synthesized $\mathrm{Ag}$ nanoparticles.

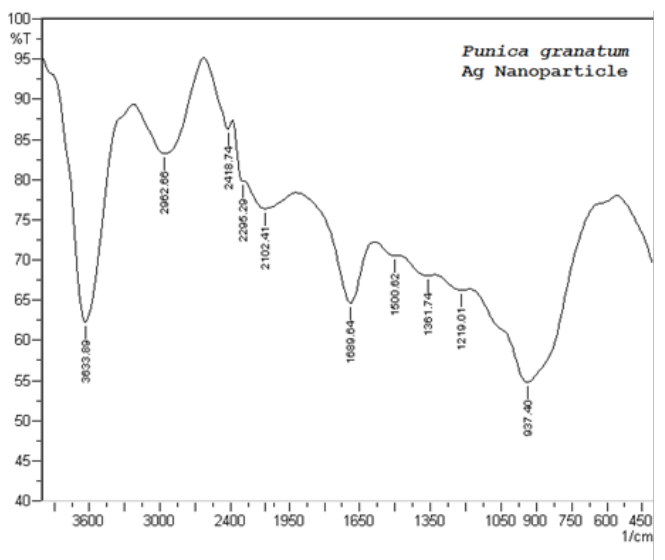

Figure 4 FT-IR spectrum of Punica granatum mediated synthesized silver nano-particles.

\section{Conclusion}

This study describes the synthesis of silver nanoparticles from the aqueous leaf extracts of Punica granatum and their characterization. On the basis of observations of the present study it is concluded that the aqueous silver ions exposed to the aqueous extract of Punica granatum were reduced and nanoparticles were synthesized. The change in the colour of the solution containing the $\mathrm{AgNO}_{3}$ solution and aqueous leaf extract of Punica granatum is consistent with the formation of the silver nanoparticle. The formation of silver nanoparticles were further confirmed by UV-Vis spectrophotometric and SEM analysis. This eco-friendly method could be a competitive alternative to the conventional physical/chemical methods used for synthesis of silver nanoparticles and thus has potential to be used in biomedical applications etc.

\section{Acknowledgements}

The Authors Acknowledge the help and facilities made available by the University Department of Zoology, Ranchi University, Ranchi and Department of Zoology, St. Xavier's College, Ranchi. The Authors are further grateful to Central Instrumentation Facility (CIF),
Birla Institute of Technology, Mesra, Ranchi for helping in the SEM, FTIR and UV-Vis analysis. The authors acknowledge the help and motivational support from the Head, Department of Zoology, St. Xavier's College, Ranchi and the Principal, St. Xavier's College, Ranchi.

\section{Conflict of interest}

The author declares no conflict of interest.

\section{References}

1. Phanjom P, Sultana A, Sarma H, et al. Plant mediated synthesis of silver nanoparticles using Elaegnus latifolia leaf extract. Dig J of Nanomat and Biostr. 2012;7(3):1117-1123.

2. Popescu M, Velea A, Lorincai A. Biogenic production of nanoparticles. Dig J of Nanomater Biostr. 2010;5(4):1035-1040.

3. Baruwati B, Polshettiwar V, Varma RS. Glutathione promoted expeditious green synthesis of silver nanoparticles in water using microvawes. Green Chem. 2009;11(7):926-930.

4. Ahmed S, Ahmad M, Swami BL, et al. A Review on plants extract mediated synthesis of silver nanoparticles for antimicrobial applications: a green expertise. Journal of Advance Research. 2016;7(1):17-28.

5. Avinash I, Mahendra R, Aniket G, et al. Fusarium solani: A novel biological agent for the extracellular synthesis of silver nanoparticles. $J$ Nanopart Res. 2009;11:2079-2085.

6. Mokhtari M, Deneshpojouh S, Seyedbagheri S, et al. Biological synthesis of very small silver nano particles by culture supernatant of Klebsiella pneumonia. Materials Research Bulletin. 2009;44(6):1415-1421.

7. Jha AK, Prasad K. A green low-cost biosynthesis of $\mathrm{Sb}_{2} \mathrm{O}_{3}$ nanoparticles. Biochemical Engineering Journal. 2009;43(3):303-306.

8. Kathiresan K, Manivannan S, Nabeel AM, et al. Studies on silver nanoparticles synthesized by a marine fungus Penicilliumfellutanum isolated from coastal mangrove sediment. Bioenterfaces. 2009;71(1):133137.

9. Ahmad A, Senapati S, Khan MI Kumar R, et al. Extracellular biosynthesis of monodisperse gold nanoparticles by a novel extreme ophillic actinomycete Thermonospora sp. Langmuir. 2003;19(8):3550-3553.

10. Dujardin E, Peet C, Stubbs G, et al. Organization of metallic nanoparticles using tobacco mosaic virus templates. NanoLett. 2003;3(3):413-417.

11. Kalishwaralal K, Deepak V, Pandian RK, et al. Biosynthesis of silver and gold nanoparticles using Brevibacterium casei. Colloids Surf B Biointerfaces. 2010;77(2):257-262.

12. Altuner EM. Investigation of antimicrobial activity of Punica granatum L. fruit peel ash used for protection against skin infections as folk remedies especially after maile circumcision. African Journal of Microbial Research. 2011;5(20):3339-3342.

13. Qnais EY, Elokda AS, Abu Ghalyun YY, et al. Antidiarrheal activity of aqueous extract of Punica granatum (pomegranate) peels. Pharm Biol. 2007;9(9):715-720.

14. Arun N, Singh DP. Punica granatum: a review on pharmacological and therapeutic properties. IJPSR. 2012;3(5):1240-1245.

15. Choi JG, Kang OH, Lee YS, et al. In vitro and in vivo antibacterial activity of Punica granatum peel ethanol extract against Salmonella. Evid Based Complement Alternative Medicine. 2011;1-8.

16. Kumar M, Dandapat S, et al. Phytochemical screening and antibacterial activity of aqueous leaf extract of Punica granatum. Balneo Research Journal. 2015;6(3):168-171 
17. Kumar M, Sinha MP. Green Nanotechnology: Synthesis of Silver nanoparticles using aqueous leaf extract of Swertia chirayita. Not Sci Biol. 2017;9(3):443-448.

18. Ahmed S, Saifullah, Ahmad M, et al. Green synthesis of silver nanoparticles using Azadirachta indica aqueous leaf extract. Journal of Radiation Research and Applied Sciences. 2016;9(1):1-7.

19. Kumar M, Dandapat S, Kumar A, et al. Anti-typhoid activity of Adhatoda vasica and Vitex negundo. Persian Gulf Crop Protection. 2013;2(3):6475.

20. Stuart B. Infrared spectroscopy: Fundamentals and Applications. John Wiley \& Sons; 2004. 199 p.

21. Silverstein RM, Bassler GC, Morril TC. Spectrometric identification of organic copounds. 4th edn. New York: John Wiley \& Sons; 1981.

22. Shankar SS, Rai A, Ankamwar B, et al. Biological synthesis of triangulargoldnanoprisms. Nat Mater. 2004;3(7):482-488.

23. Shankar SS, Rai A, Ahmad M, et al. Rapid synthesis of Au, Ag, and bimetallic $\mathrm{Au}$ Core-Ag shell nanoparticles using Neem (Azadirachta indica) leaf broth. J Colloid Interface Sci. 2004;275(2):496-502.

24. Panigrahi, Tamasa. Synthesis and characterization of silver nanoparticles using leaf extract of Azadirachta indica. Rourkela. Department of Life Science. Orissa: National institute of Technology; 2013. 69 p.

25. Amendola V, Bakr OM, Stellacci F. A study of surface plasmon resonance of silver nanoparticles by the discrete dipole approximation method: effect of shape, size, structure, and assembly. Plasmonics. 2010;5(1):85-97.

26. Dhanlakshmi T, Rajendran S. Synthesis of silver nanoparticles using Tridax procumbens and its antimicrobial activity. Scholars Research Library. 2012;4(3):1289-1293.
27. Parashar VR, Parashar, Sharma B, et al. Parthenium leaf extract mediated synthesis of silver nanoparticles: a novel approach towards weed utilization. Digest Journal of Nanomaterials and Biostructures. 2008;4(1):45-50.

28. Jain D, Daima H. K,Kachhwaha S, et al. Synthesis of plant-mediated silver nanoparticles using papaya fruit extract and evaluation of their antimicrobials. Digest Journal of Nanomaterials and Biostructures. 2009;4(3):557-563.

29. Geethalakshmi R, Sarada DVL. Synthesis of plant-mediated silver nanoparticles using Trianthemadecandra extract and evaluation of their anti-microbial activities. International Journal of Engineering Science and Technology. 2010;2(5):970-975.

30. Firdhouse M, Jannathul P, Lalitha K, et al. Novel synthesis of silver nanoparticles using leaf ethanol extract of Pisonia grandis (R. Br). Der Pharma Chemica. 2012;4(6):2320-2326.

31. Han G, Ghosh P, Rotello VM. Functionalized gold nanoparticles for drug delivery. Nanomedicine. 2007;2(1):113-123.

32. Haverkamp RG, Marshall AT. The mechanism of metal nanoparticle formation in plants: limits on accumulation. $J$ Nanopart Res. 2009;11(6):1453-1463.

33. Coates J. Interpretation of infrared spectra, a practical approach. In Encyclopedia of Analytical Chemistry. RA Meyers editor. Chichester: John Wiley \& Sons Ltd; 2000. p. 10815-10837.

34. Kalishwaralal K, Deepak V, Ram PS, et al. Biosynthesis of gold nanocubes from Bacillus lichemiformi. Bioresearch and technology. 2008;100(21):5356-5358. 